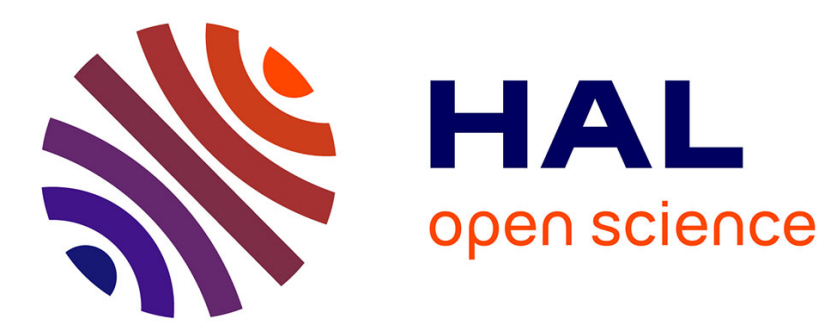

\title{
Molecular cytogenetics and flow cytometry reveal conserved genome organization in Pinus mugo and $\mathrm{P}$. uncinata
}

Bogunić, Siljak-Yakovlev, Muratović, Pustahija, Medjedović

\section{To cite this version:}

Bogunić, Siljak-Yakovlev, Muratović, Pustahija, Medjedović. Molecular cytogenetics and flow cytometry reveal conserved genome organization in Pinus mugo and P. uncinata. Annals of Forest Science, 2011, 68 (1), pp.179-187. 10.1007/s13595-011-0019-9 . hal-00930755

\section{HAL Id: hal-00930755 \\ https://hal.science/hal-00930755}

Submitted on 1 Jan 2011

HAL is a multi-disciplinary open access archive for the deposit and dissemination of scientific research documents, whether they are published or not. The documents may come from teaching and research institutions in France or abroad, or from public or private research centers.
L'archive ouverte pluridisciplinaire HAL, est destinée au dépôt et à la diffusion de documents scientifiques de niveau recherche, publiés ou non, émanant des établissements d'enseignement et de recherche français ou étrangers, des laboratoires publics ou privés. 


\title{
Molecular cytogenetics and flow cytometry reveal conserved genome organization in Pinus mugo and $P$. uncinata
}

\author{
Faruk Bogunić • Sonja Siljak-Yakovlev • \\ Edina Muratović • Fatima Pustahija • Safer Medjedović
}

Received: 29 October 2009 / Accepted: 6 February 2010/Published online: 15 February 2011

(C) INRA and Springer Science+Business Media B.V. 2011

\begin{abstract}
- Introduction The most common representatives of the European mountain pine complex (Pinus mugo s.l.) are P. mugo s.s. and Pinus uncinata.

- Materials and methods Genome characterization of $P$. mugo and $P$. uncinata was studied using fluorescence in situ hybridization of $5 \mathrm{~S}$ and 18-5.8-26S rDNA, fluorochrome banding for heterochromatin characterization, and flow cytometry for DNA content measurement.

- Results and discussion Distribution of 5S and 18S rDNA showed identical patterns for both pine species. In contrast, heterochromatin patterns revealed slight differences in the number and position of bands between these two pines. Genome size analysis of $21 P$. mugo populations and one $P$. uncinata population revealed no significant variations across seven European countries. The mean genome size (2C DNA) for the 21 P. mugo populations was $42.56 \pm$ $0.79 \mathrm{pg}$, equivalent to $41.62 \times 10^{3} \mathrm{Mbp}$, and ranged from
\end{abstract}

Handling Editor: Luc Pâques

F. Bogunić $(\bowtie) \cdot$ F. Pustahija $\cdot$ S. Medjedović

Faculty of Forestry, University of Sarajevo,

Zagrebačka 20,

Sarajevo 71000, Bosnia and Herzegovina

e-mail: faruk_bogunic@yahoo.com

S. Siljak-Yakovlev

Univ. Paris-Sud, CNRS, AgroParisTech,

UMR 8079, Ecologie, Systématique, Evolution,

Bâtiment 360,

91405 Orsay Cedex, France

F. Bogunić $\cdot$ S. Siljak-Yakovlev $\cdot$ E. Muratović $\cdot$ F. Pustahija Laboratory for research and protection of endemic resources, Department of Biology, Faculty of Sciences, Zmaja od Bosne 33, University of Sarajevo,

Sarajevo 71000, Bosnia and Herzegovina
41.08 to $43.95 \mathrm{pg}$. No relationships were observed between nuclear DNA content and geographic origin of the studied populations.

- Conclusions Our results reveal that the mechanisms shaping molecular cytogenetic organization and genome size did not profoundly differentiate the genomes of $P$. mugo and $P$. uncinata. Observed variations in heterochromatin patterns indicate ongoing divergence processes in the genomes of the two pines.

\section{Introduction}

Pinus mugo Turra s.l. (subgenus Pinus, section Pinus) encompasses an aggregate of heterogeneous pine populations mostly distributed in mountain ranges of southern and central Europe. Phenotypic plasticity, ecological and geographical differentiation of populations and their possible hybridization with Pinus sylvestris $\mathrm{L}$. have led to a complicated taxonomic situation within the complex. P. mugo s.s. (dwarf mountain pine) and P. uncinata (DC. in Lam. and DC.) Domin (mountain pine) are the most common representatives of the complex. The complex is divided into two geographical groups: the eastern division, encompassing P. mugo s.s. populations (the eastern Alps, Dinaric Alps, Carpathians, Mts. Rila and Pirin, and some disjunctions in Italy and the western Alps) (Christensen 1987; Hamerník and Musil 2007), and the western division, encompassing P. uncinata populations distributed on the Iberian mountain ranges, Pyrenees, Massif Central and western Alps (Christensen 1987; Hamerník and Musil 2007). P. mugo s.s. and $P$. uncinata can be easily distinguished using morphological and anatomical characters in allopatric areas (Boratyńska and Bobowicz 2001; Boratyńska and Boratyński, 2007; Christensen 1987; Marcysiak and Boratyński, 2007), 
although molecular markers indicate the absence of species differentiation (Heuertz et al. 2010; Monteleone et al. 2006). There are two predominant hypotheses to define this situation taxonomically: the first treats these pines as independent species (Gaussen et al. 1993; Prus-Glowacki et al. 1998), while the second considers them as two $P$. mugo subspecies, mugo and uncinata (Ramond ex DC. in Lam. and DC.) Domin (Boratyńska and Bobowicz 2001; Christensen 1987). Besides these two pines, several taxa from Central Europe are also included within the P. mugo s.l. complex (Pinus rotundata Link, Pinus uliginosa Neumann and Pinus uliginosa $x$ pseudopumilio (Willk.) Beck). The mentioned taxa represent ecologically specialized and isolated populations to peat bogs or hybrid derivates from different parental combinations.

Despite their economic and ecological importance, the understanding of molecular cytogenetics and genomics of forest trees has not progressed to the same extent as in herbaceous plants. To date, molecular cytogenetics employing fluorescent in situ hybridization have been performed for only 23 out of 111 pine species.

Interspecific differences have been revealed among Eurasian pines of section Pinus using fluorescent in situ hybridization (FISH) and fluorescent banding techniques on P. sylvestris (Hizume et al. 2002; Karvonen et al. 1993; Lubaretz et al. 1996), Pinus densiflora and Pinus thunberghii (Hizume et al. 2002), Pinus tabulaeformis, Pinus yunanensis, Pinus densata, Pinus massoniana, Pinus merkussi (Liu et al. 2003) and Pinus nigra (Bogunić et al. 2011; Hizume et al. 2002). All these species possessed two $5 \mathrm{~S}$ rDNA loci except $P$. massoniana (1 locus) and $P$. densata, which had three 5S rDNA sites. The number of both intercalary and proximal $18 \mathrm{~S}$ rDNA loci ranged from 8 to 24 (Hizume et al. 2002; Liu et al. 2003).

Genome size studies have now examined almost $87 \%$ of all Pinus species (Grotkopp et al. 2004). Genome size has been accepted as an important and useful parameter for inferences in different fields of species biology (Bennett and Leitch 2005). Pines belong to the group of species with large genomes, ranging from 22.10 to $36.89 \mathrm{pg}$ per $1 \mathrm{C}$ (Murray 1998). Genome size in pines is correlated with different attributes of species biology and life history strategies (Grotkopp et al. 2004), but is also strongly influenced by retrotransposon dynamics and its divergence within pine genomes (Morse et al. 2009). However, only a few studies have examined genome size variation at the population level (Bogunic et al. 2003, 2007).

The main goal of this study was to analyse genome organization of $P$. mugo and P. uncinata by means of FISH for $5 \mathrm{~S}$ and $18 \mathrm{~S}$ rDNA, fluorochrome staining with chromomycin A (CMA) and 4'-6-diamidino-2-phenylindole (DAPI) for heterochromatin characterization, and flow cytometry for DNA content. We addressed the following questions: (a) Do these two pines differ significantly in their genome organization? (b) Is genome organization of P. mugo and P. uncinata similar to that in the other pine species from the subsection Pinus, particularly their closest relative $P$. sylvestris? c) Does genome size significantly vary among different $P$. mugo populations?

\section{Material and methods}

\subsection{Plant materials}

Fresh leaves and seeds from five individual trees growing in 21 natural populations of Pinus mugo and one population of $P$. uncinata were collected (Table 1). In the study, we used the nomenclature system with $P$. mugo and $P$. uncinata as independent species, following Gaussen et al. (1993). Vouchers (cones, seeds and leaves for morphological analyses) were deposited in the Herbarium of Faculty of Forestry, University of Sarajevo.

\subsection{Molecular cytogenetic analysis}

Slide preparations Seeds were sown in moist filter paper Petri dishes at room temperature. Primary root tip samples of approximately $1-1.5 \mathrm{~cm}$ length were pre-treated in $0.05 \%$ aqueous colchicine solution for $24 \mathrm{~h}$ at room temperature and fixed in ice-cold Carnoy's fixative (ethanol/acetic acid, 3:1 v/v) for $24 \mathrm{~h}$. Finally, the fixed root tips were washed in distilled water and kept in $70 \%$ ethanol at $-20^{\circ} \mathrm{C}$ until use.

The meristems were hydrolyzed for $60 \mathrm{~min}$ in a moist chamber at $37^{\circ} \mathrm{C}$ in an enzyme mixture $[3 \%$ cellulase R10 (Yakult Honsha Co., Tokyo Japan), 1\% pectyolase Y-23 (Seishin corporation, Tokyo Japan) and 4\% hemicellulase (Sigma Aldrich Co., Steinheim, Germany)] in citrate buffer $(\mathrm{pH}=4.2)$. Chromosome spreads were then obtained using conventional squashing in a drop of $45 \%$ acetic acid. The coverslips were removed after freezing at $-80^{\circ} \mathrm{C}$ for $24 \mathrm{~h}$.

Fluorescent in situ hybridization Double target FISH of 5 and 18-5.8-26S rDNA was performed following the procedures of (Bogunić et al. 2011) and Siljak-Yakovlev et al. (2002).

The $18 \mathrm{~S}$ rDNA was a $4 \mathrm{~kb}$ clone from the EcoRI fragment containing 18-5.8-26S rDNA sequences from Arabidopsis thaliana labelled with direct fluorochrome Cy3 (Amersham Co., Uppsala, Sweden). The 5S rDNA probe was the pTa794 clone (Gerlach and Dyer 1980) containing a 410 bp BamHI fragment from the Triticum vulgare genome labelled with digioxigenin-11-dUTP (Roche Diagnostics, Basel, Switzerland). The slides were counterstained and mounted in Vectashield mounting DAPI medium (Vector Laboratories, Peterborough, UK). 
Table 1 The origin of plant material and geographic characteristics of populations analysed (Pinus mugo (M); Pinus uncinata (U))

\begin{tabular}{|c|c|c|c|c|}
\hline Population & Locality & Latitude & Longitude & Altitude (m) \\
\hline \multicolumn{5}{|l|}{ M } \\
\hline M1 & Rušje, Julijske Alpe, Slovenia & $46^{\prime} 25^{\prime \prime} 10^{\circ} \mathrm{N}$ & $13^{\prime} 49^{\prime \prime \prime} 17^{\circ} \mathrm{E}$ & 2,000 \\
\hline M2 & Dobrča, Karavanke, Slovenia & $46^{\prime} 23^{\prime \prime} 59^{\circ} \mathrm{N}$ & $14^{\prime} 15^{\prime \prime} 00^{\circ} \mathrm{E}$ & 1,590 \\
\hline M3 & Crni vrh, Mt. Bjelašnica, Bosnia and Herzegovina (BH) & $43^{\prime} 44^{\prime \prime} 00^{\circ} \mathrm{N}$ & $18^{\prime} 06^{\prime \prime} 00^{\circ} \mathrm{E}$ & 1,780 \\
\hline M4 & Mt. Kamešnica, BH & $43^{\prime} 46^{\prime \prime} 00^{\circ} \mathrm{N}$ & $16^{\prime} 50^{\prime \prime} 02^{\circ} \mathrm{E}$ & 1,645 \\
\hline M5 & Tisovica, Mt. Prenj, BH & $43^{\prime} 33^{\prime \prime} 00^{\circ} \mathrm{N}$ & $17^{\prime} 59^{\prime \prime} 00^{\circ} \mathrm{E}$ & 1,600 \\
\hline M6 & Blidinje, Mt. Čvrsnica, BH & $43^{\prime} 35^{\prime \prime} 11^{\circ} \mathrm{N}$ & $17^{\prime} 34^{\prime \prime} 18^{\circ} \mathrm{E}$ & 1,600 \\
\hline M7 & Krupna navala, Mt. Čabulja, BH & $43^{\prime} 30^{\prime \prime} 15^{\circ} \mathrm{N}$ & $17^{\prime} 36^{\prime \prime} 50^{\circ} \mathrm{E}$ & 1,522 \\
\hline M8 & Crno jezero, Mt. Treskavica, BH & $43^{\prime} 34^{\prime \prime} 14^{\circ} \mathrm{N}$ & $18^{\prime} 22^{\prime \prime} 30^{\circ} \mathrm{E}$ & 1,650 \\
\hline M9 & Prijevor, Mt. Maglić, BH & $43^{\prime} 14^{\prime \prime} 39^{\circ} \mathrm{N}$ & $18^{\prime} 44^{\prime \prime} 10^{\circ} \mathrm{E}$ & 1,670 \\
\hline M10 & Mt. Golija, BH & $43^{\prime} 58^{\prime \prime} 07^{\circ} \mathrm{N}$ & $16^{\prime} 51^{\prime \prime} 40^{\circ} \mathrm{E}$ & 1,750 \\
\hline M11 & Mali Troglav, Mt. Troglav, BH & $43^{\prime} 54^{\prime \prime} 18^{\circ} \mathrm{N}$ & $16^{\prime} 37^{\prime \prime} 00^{\circ} \mathrm{E}$ & 1,660 \\
\hline M12 & Gola Jahorina, Mt. Jahorina, BH & $43^{\prime} 42^{\prime \prime} 47^{\circ} \mathrm{N}$ & $18^{\prime} 34^{\prime \prime} 50^{\circ} \mathrm{E}$ & 1,908 \\
\hline M13 & Mt. Vran, BH & $43^{\prime} 40^{\prime \prime} 11^{\circ} \mathrm{N}$ & $17^{\prime} 28^{\prime \prime} 51^{\circ} \mathrm{E}$ & 1,900 \\
\hline M14 & Šatorsko jezero, Mt. Šator, BH & $44^{\prime} 09^{\prime \prime} 18^{\circ} \mathrm{N}$ & $16^{\prime} 36^{\prime \prime} 30^{\circ} \mathrm{E}$ & 1,550 \\
\hline M15 & Mt. Crvanj, BH & $43^{\prime} 23^{\prime \prime} 47^{\circ} \mathrm{N}$ & $18^{\prime} 14^{\prime \prime} 00^{\circ} \mathrm{E}$ & 1,567 \\
\hline M16 & Virovi, Mt. Ošlak, Kosovo & $42^{\prime} 12^{\prime \prime} 07^{\circ} \mathrm{N}$ & $29^{\prime} 52^{\prime \prime} 15^{\circ} \mathrm{E}$ & 1,800 \\
\hline M17 & Roženski kukovi, Mt. Velebit, Croatia & $44^{\prime} 46^{\prime \prime} 11^{\circ} \mathrm{N}$ & $14^{\prime} 59^{\prime \prime} 43^{\circ} \mathrm{E}$ & 1,800 \\
\hline M18 & Kolašin, Mt. Bjelasica, Monte Negro & $42^{\prime} 52^{\prime \prime} 00^{\circ} \mathrm{N}$ & $19^{\prime} 40^{\prime \prime} 00^{\circ} \mathrm{E}$ & 1,800 \\
\hline M19 & Tyrol, Austria & $47^{\prime} 57^{\prime \prime} 54^{\circ} \mathrm{N}$ & $15^{\prime} 53^{\prime \prime} 18^{\circ} \mathrm{E}$ & 1,850 \\
\hline M20 & North Austria, Austria & $47^{\prime} 12^{\prime \prime} 57^{\circ} \mathrm{N}$ & $11^{\prime} 20^{\prime \prime} 30^{\circ} \mathrm{E}$ & 1,850 \\
\hline M21 & Prokoško jezero, Mt. Vranica, BH & $43^{\prime} 56^{\prime \prime} 14^{\circ} \mathrm{N}$ & $17^{\prime} 46^{\prime \prime} 02^{\circ} \mathrm{E}$ & 1,650 \\
\hline $\mathrm{U}$ & Bonifaca, Pyrenees, Spain & $47^{\prime} 22^{\prime \prime} 94^{\circ} \mathrm{N}$ & $03^{\prime} 22^{\prime \prime} 94^{\circ} \mathrm{E}$ & 1,750 \\
\hline
\end{tabular}

Fluorochrome banding To detect GC-rich DNA regions, we used chromomycin $\mathrm{A}_{3}\left(\mathrm{CMA}_{3}\right.$, Sigma Aldrich Co., Steinheim, Germany) following the procedure of SiljakYakovlev et al. (2002). After CMA staining, the slides were destained in an ethanol series (70\%, 90\% and 100\%) and prepared for in situ hybridization.

Microscopy and chromosome analysis Observation of chromosome plates was performed under a Zeiss Axiophot epifluorescence microscope using filters $01,07,15$ and the triple filter set 25 . FISH signals were captured and analysed with a highly sensitive CCD camera (Princeton Instruments, Evry, France). The single images of 5S, $18 \mathrm{~S}$ rDNA patterns and DAPI banding were overlapped to obtain a final FISH image, using a MetaVue Image Analyser. The images were processed for colour contrast and brightness only, using Adobe Photoshop (Adobe Systems, Switzerland).

The chromosomes were ordered according to decreasing relative length and complementary pairing decided on the basis of CMA, DAPI, 5 and $18 \mathrm{~S}$ patterns. At least five individuals per population were analysed to construct the idiograms for $P$. mugo and $P$. uncinata. The longest chromosome pair was labelled as I and the shortest as XII. The locations of signals on the ideograms in this paper represent the relative position of these signals on the chromosomes.

\subsection{Flow cytometry}

Genome size was estimated by flow cytometry according to the procedure described by Marie and Brown (1993), making slight modifications to the internal standard, concentration of RNase and ethidium bromide to adapt the method to pines (Bogunic et al. 2003, 2007). In this study, we used leaf material as the source of $2 \mathrm{C}$ genome size data.

Nuclear genome size was determined using an ELITE ESP flow cytometer with an argon laser emitting $40 \mathrm{~mW}$ at $488 \mathrm{~nm}$, taking fluorescence at $610 \pm 15 \mathrm{~nm}$. Galbraith's buffer (Galbraith et al. 1983), containing 0.1\% Triton, $1 \%(w / v)$ polyvinylpyrrolidine 10,000 and fresh $10 \mathrm{mM}$ sodium metabisulfite, was used for nuclei isolation. Nuclei were stained with the DNA intercalating fluorochrome dye ethidium bromide (Sigma, St. Louis, Mo). Pine needles and wheat leaves (Triticum aestivum Chinese Spring, as the internal standard, $2 \mathrm{C}=30.9 \mathrm{pg}$ ) were chopped simultaneously with a razor blade in cold buffer and filtered through a $48 \mu \mathrm{m}$ nylon mesh. RNase was then added to 
$5 \mu \mathrm{g} / \mathrm{ml}$. Finally, ethidium bromide was added to a final concentration of $70 \mu \mathrm{g} / \mathrm{ml}$. The suspension of intact isolated nuclei was kept on ice for $30 \mathrm{~min}$ before analysis of at least 5,000 nuclei. Absolute 2C value (pg DNA) was calculated from the ratio between internal standard fluorescence $(2 \mathrm{C}$ wheat) and pine sample fluorescence. Each population comprised five individuals that were measured separately, often with repetition. All analyses were performed by the same operator on the same machine.

Genome size data was analysed by SPSS ver. 15 for Windows. One-way analysis of variance was used to analyse the mean genome size of the populations. Additionally, post hoc Tukey's honestly significant difference (HSD) and Scheffe's multiple range tests were used to test for differences among the populations. Spearman's correlation tests were employed to check whether genome size was correlated with latitude, longitude and altitude.

\section{Results}

\section{1 rDNA loci pattern and heterochromatin distribution}

Morphometric features of $P$. mugo and P. uncinata karyotypes were similar to those of all other studied pine species from the subgenus Pinus. The first ten chromosome pairs were metacentric while the two smallest pairs were submetacentric.

Only plates with reproducible intensity and position of the targeted markers were analysed for the P. mugo and $P$. uncinata accessions. Representative microphotographs of CMA and FISH patterns and a single-homologue chromosome of each complementary pair after FISH are presented in Fig. 1. Schematic representation of the number and relative position of 5S and 18S rDNA loci, CMA and DAPI signals are shown on idiograms (Fig. 1).

Not surprisingly, an identical 5S rDNA pattern was found in both $P$. mugo and $P$. uncinata. Two loci of 5S rDNA were observed: the minor $5 \mathrm{~S}$ rDNA locus was located in an intercalary position on the short arm of chromosome pair I, and the other locus was found in a subtelomeric position on the longer arm of pair V (Fig. 1(A and B, arrows)).

Distribution of $18 \mathrm{~S}$ rDNA loci showed stable patterns in the karyotypes of both pine species. The FISH experiment revealed six intercalary $18 \mathrm{~S}$ rDNA loci distributed across the six chromosome pairs I, II, V, VII, VIII and X, in both pine species (Fig. 1(A, B and C)). All 18S rDNA loci were co-localized with intercalary CMA signals.

Analysis of CMA banding revealed slight variation between the pines in the presence and position of one of the CMA signals (Fig. 1(A1, B1, D and D1)). Pinus mugo had 34 CMA signals distributed across 11 chromosome pairs (Fig. 1(A1 and D)), with no signals on pair VI. Five chromosome pairs possessed only centromeric CMA signals
(III, IV, IX, XI and XII), while six pairs had both centromeric and intercalary CMA signals (I, II, V, VII, VIII and X).

P. uncinata had less CMA signals (32) than P. mugo, but these were also distributed across 11 chromosome pairs (Fig. 1(B1 and D1)). Five pairs showed only centromeric signals (III, IV, IX, XI and XII), while one (II) had only intercalary signals. Both centromeric and intercalary CMA signals were observed on five chromosome pairs (I, V, VII, VIII and X).

DAPI banding after FISH displayed many more signals of unspecific heterochromatin in centromeric and proximal positions (Fig. 1(A, B and C)). The average number of DAPI signals for $P$. mugo was 64 while $P$. uncinata had 48 . All chromosome pairs had centromeric DAPI signals, while distribution of intercalary signals was not uniform either within P. mugo or P. uncinata karyotypes. Three chromosome types could be identified: those without intercalary signals, those carrying one DAPI signal and those with two DAPI signals. The only exception was pair II in P. mugo, which had three intercalary signals (Fig. 1(A, B and C)).

\subsection{Genome size analysis}

All populations of $P$. mugo and $P$. uncinata had typically large genomes (Table 2). The mean fluorescence indices $\left(2 \mathrm{C}_{\text {Pinus }} / 2 \mathrm{C}_{\text {Triticum }}\right)$ obtained from DNA histograms had coefficients of variation from $0.82 \%$ to $3.89 \%$. Mean nuclear DNA content $(2 \mathrm{C} \mathrm{DNA} / \mathrm{pg})$ for $21 \mathrm{P}$. mugo populations was $42.56 \pm 0.79 \mathrm{pg}$, equivalent to $41.62 \times 10^{9} \mathrm{bp}$ (1 pg DNK $=0.978 \mathrm{Mbp}$, Doležel et al. 2003), and ranged from 41.08 (M16) to 43.95 (M1) pg (Table 2). Analysis of variance $\left(F_{21,109}=3.53 ; p<0.000\right)$ showed significant differences among the populations. Tukey's HSD tests detected differences between the populations M1 vs. M10 $(t=2.762)$ and M1 vs. M16 $(t=2.87)$ at $p<0.01$. At $p<0.001$, a difference was observed only between M1 and M16. Using the more conservative Scheffe's test, no differences were found among populations or between the $P$. mugo and $P$. uncinata accessions.

No patterns were revealed in the relationships between the nuclear DNA content and geographic parameters analysed: DNA-latitude ( $r=0.316 ; N=22)$, DNA-longitude $(r=-0.045 ; N=22)$ and DNA-altitude $(r=0.357 ; N=22)$.

\section{Discussion}

\subsection{Chromosome organization of rDNA}

Fluorescent in situ hybridization of 5S and 18-26S rDNA loci, and heterochromatin characterization by fluorochrome banding showed similar genome organization of $P$. mugo and $P$. uncinata. Our results fit into the phylogenetic 
Fig. 1 Metaphase chromosome plates of Pinus mugo and Pinus uncinata after in situ hybridization with $5 \mathrm{~S}$ and $18 \mathrm{~S}$ rDNA probes and CMA staining. FISH/CMA: P. mugo $(A, A 1)$; $P$. uncinata $(B, B 1)$; singlehomologue chromosomes from karyotypes of $P$. mugo $(M 1-$ M12) and P. uncinata (U1-U12) after FISH $(C)$; 5S rDNA, green signals; $18 \mathrm{~S}$ rDNA, red signals; DAPI, pale blue signals; idiograms of $P$. mugo and $P$. uncinata $(D, D 1)$. 5S rDNA, green signals; $18 \mathrm{~S}$ rDNA, red signals; CMA, yellow signals; DAPI, blue signals. Scale bar $=10 \mu \mathrm{m}$. Arrows indicate the position of $5 \mathrm{~S}$ rDNA signals
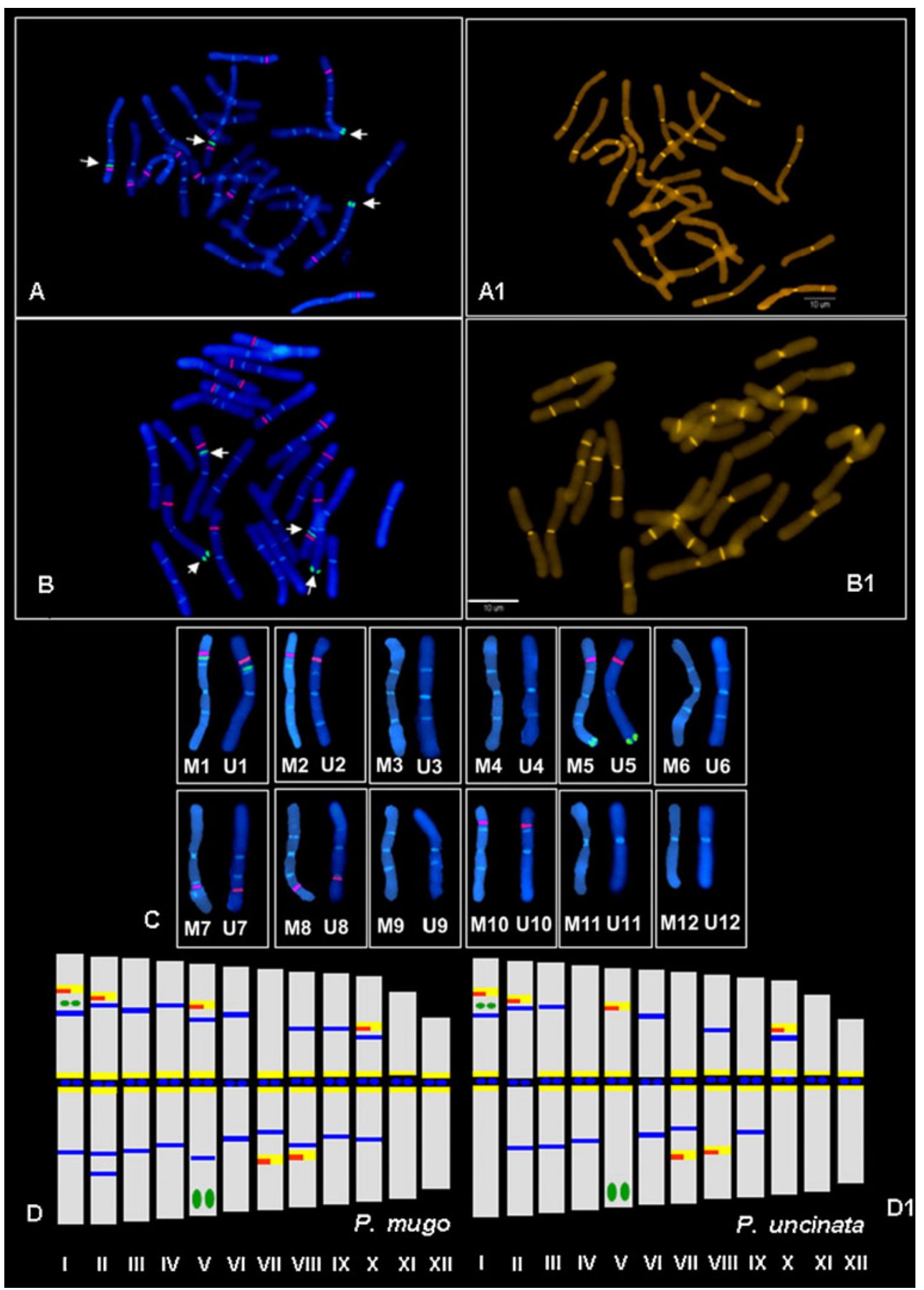

context of section Pinus, as they reflect a similar chromosome organization.

The 5S rDNA pattern of $P$. mugo and $P$. uncinata is typical of their relatives from the same section. In most pine species from section Pinus, two 5S rDNA loci are present on different chromosome pairs (Hizume et al. 2002; Liu et al. 2003). The only exceptions from this normal pattern are $P$. massoniana, which has one 5S rDNA locus and $P$. densata, a hybrid derived from Pinus tabuleformis and P. yunnanensis, which has three (Liu et al. 2003). A remarkable example of conserved 5S rDNA pattern is seen in the group of closely related pines $P$. tabuleformis, $P$. densata, $P$. yunnanensis and P. merkussi, which have a strict Asian geographic distribution: both their 5S rDNA loci are positioned on the same chromosome pairs (Liu et al. 2003). In contrast, P. sylvestris, $P$. densiflora, $P$. thunberghii and $P$. nigra have more variable 5S rDNA loci patterns but their phylogenetic positions are somewhat different within the section Pinus. Despite their constant number and position (intercalary and subterminal) on chromosomes, $5 \mathrm{~S}$ rDNA loci are distributed on different 
Table 2 Nuclear DNA content (2C) for populations of Pinus mugo (M) and Pinus uncinata $(\mathrm{U})$

\begin{tabular}{|c|c|c|c|c|c|}
\hline Population & $\begin{array}{l}\text { Number of analysed } \\
\text { individuals }\end{array}$ & Mean & SD & Min-max & $\begin{array}{l}\text { Coefficient of } \\
\text { variation }(\%)\end{array}$ \\
\hline \multicolumn{6}{|l|}{ M } \\
\hline M1 & 5 & 43.95 & 0.46 & $43.35-44.59$ & 1.05 \\
\hline M2 & 5 & 43.04 & 0.98 & $41.57-44.06$ & 2.28 \\
\hline M3 & 5 & 43.51 & 0.60 & $42.96-44.42$ & 1.37 \\
\hline M4 & 5 & 43.01 & 0.38 & $42.67-43.47$ & 0.86 \\
\hline M5 & 5 & 43.15 & 0.68 & $42.55-44.23$ & 1.57 \\
\hline M6 & 5 & 42.97 & 0.62 & $42.07-43.77$ & 1.44 \\
\hline M7 & 5 & 41.57 & 0.57 & $40.42-41.52$ & 2.78 \\
\hline M8 & 5 & 42.05 & 0.62 & $41.40-42.80$ & 1.48 \\
\hline M9 & 5 & 42.94 & 1.37 & $41.44-44.90$ & 3.18 \\
\hline M10 & 5 & 43.84 & 0.36 & $43.30-44.20$ & 0.82 \\
\hline M11 & 5 & 42.18 & 0.48 & $41.50-42.94$ & 1.14 \\
\hline M12 & 5 & 43.08 & 0.81 & $42.26-44.27$ & 1.89 \\
\hline M13 & 5 & 42.34 & 1.14 & $41.26-44.02$ & 2.69 \\
\hline M14 & 5 & 41.64 & 1.20 & $40.24-43.39$ & 2.87 \\
\hline M15 & 5 & 41.72 & 0.56 & $41.24-42.68$ & 1.17 \\
\hline M16 & 5 & 41.08 & 0.88 & $39.91-42.25$ & 2.16 \\
\hline M17 & 5 & 42.58 & 1.33 & $40.79-44.33$ & 3.54 \\
\hline M18 & 5 & 42.89 & 1.10 & $41.60-44.39$ & 2.56 \\
\hline M19 & 5 & 42.63 & 0.96 & $41.60-43.96$ & 2.29 \\
\hline M20 & 5 & 41.96 & 0.52 & $41.36-42.63$ & 1.22 \\
\hline M21 & 5 & 41.66 & 1.00 & $40.10-42.80$ & 2.39 \\
\hline Total & 105 & 42.56 & 0.79 & $41.08-43.95$ & 1.94 \\
\hline $\mathrm{U}$ & 5 & 41.98 & 1.69 & $39.93-44.50$ & 3.89 \\
\hline
\end{tabular}

chromosome pairs in the European group (Hizume et al. 2002). Pinus mugo and $P$. uncinata have 5S loci on chromosome pairs II and V (Fig. 1(C, D and D1)) and almost all other pine species analysed, except $P$. densiflora, have $5 \mathrm{~S}$ loci on the first five chromosome pairs (Hizume et al. 2002; Liu et al. 2003; Lubaretz et al. 1996). Such a distribution of $5 \mathrm{~S}$ loci might be phylogenetically constrained, and have resulted from chromosome rearrangements and structural reorganization of the genome during species evolution within the section.

The 18S rDNA patterns of our analysed species also showed no variation, either in number or position (Fig. 1 (C)). In the genus Pinus, the $18 \mathrm{~S}$ rDNA generally showed more variation than the $5 \mathrm{~S}$ rDNA pattern. The species from this section possess from four to nine interstitial loci, although previous studies also found centromeric $18 \mathrm{~S}$ rDNA signals of weaker intensity (Bogunić et al. 2011; Hizume et al. 2002; Liu et al. 2003). The species in our study showed six intercalary loci, but no centromeric loci were observed (Fig. 1(C, D and D1)). Most pine species within the section have six or seven intercalary loci (Hizume et al. 2002; Liu et al. 2003). Scots pine (P. sylvestris) is a sister species to $P$. mugo and P. uncinata (Gernandt et al.
2005), but it possesses seven (Hizume et al. 2002; Lubaretz et al. 1996) or eight (Karvonen et al. 1993) interstitial 18S rDNA loci. The different number of $18 \mathrm{~S}$ rDNA loci in $P$. sylvestris indicates that intraspecific variation cannot be excluded with certainty. Only three chromosome pairs (I, II and IX) carrying $18 \mathrm{~S}$ rDNA loci are common in karyotypes of P. mugo, P. uncinata and P. sylvestris and are probably homeologous. The phylogenetic hypothesis predicts more similar chromosome patterns in closer relatives. Thus, if we compare molecular phylogenetic data (Eckert and Hall 2006; Gernandt et al. 2005) and rDNA patterns for $P$. mugo, $P$. uncinata and $P$. sylvestris, more chromosome markers need to be employed to clarify these interrelationships at the chromosome level.

Comparison of $18 \mathrm{~S}$ rDNA pattern between $P$. mugo and $P$. uncinata is also interesting from the biogeographic standpoint. Geographic distance between the analysed $P$. mugo and $P$. uncinata accessions was more than $2,000 \mathrm{~km}$ (Balkans and Iberian peninsula) and the absence of variation in $18 \mathrm{~S}$ rDNA pattern of these species indicates conserved genomes (Fig. 1). In contrast, $P$. nigra populations from different parts of the Mediterranean showed considerable variation in the number and position of $18 \mathrm{~S}$ rDNA loci at the intraspecific 
level (Bogunić et al. 2011). Molecular clock analysis showed that evolutionary diversification of $P$. mugo and $P$. uncinata from their common ancestor can be estimated at around $22 \mathrm{Ma}$ ago while the estimate for P. nigra was around $90 \mathrm{Ma}$ (Eckert and Hall 2006). Consequently it can be assumed that both $P$. mugo and $P$. uncinata have had much less time on the evolutionary time scale to develop differences in the $18 \mathrm{~S}$ rDNA pattern during the long-term adaptation to contrasting environments in their habitats. However slight divergence of chromosomal organization is reflected by CMA and DAPI heterochromatin.

\subsection{CMA and DAPI heterochromatin patterns}

At first sight $P$. mugo and $P$. uncinata generally exhibit uniform CMA signals (Fig. 1(D and D1)). The number and position of intercalary bands are the same in both species, but a difference was observed in centromeric CMA bands. Careful analysis of types of chromosome with CMA signals slightly improves the genome distinction between these species. Four types of CMA chromosomes could be distinguished in karyotypes of the two pines. There are no chromosome pairs with only intercalary CMA signals in P. mugo, while P. uncinata has one such pair (Fig. 1(D and D1)). Furthermore, both pines have five chromosome pairs with only centromeric CMA signals (Fig. 1(D and D1)). Finally six pairs carrying both centromeric and interstitial signals were observed in $P$. mugo and five in $P$. uncinata karyotype (Fig. 1(D and D1)). Both species have one pair without any CMA signal. The slight difference in the patterns indicates weak genome divergence at GC-rich heterochromatin level between the pines in relation to rDNA organization. Interstitial CMA signals related to $18 \mathrm{~S}$ rDNA repeats do not show obvious variation within the genomes of these pines compared with centromeric signals. Centromeric CMA bands might be related to rDNA repeats (Bogunić et al. 2011) but also could also be made up from independent GC-rich sequences (Guerra et al. 2000). Different mechanisms operating at the molecular level, such as amplification of repetitive sequences, retrotransposition and heterochromatinization of these regions might be responsible for CMA differentiation along the chromosomes (Guerra et al. 2000).

Two patterns are evident after DAPI staining: one ( $P$. mugo) with more DAPI bands (64) and the second (P. uncinata) with fewer (48). Distribution of these DAPI signals along the chromosomes is typical for pine species (Bogunic et al. 2006; Hizume et al. 2002; Lubaretz et al. 1996). All centromeres, both $\mathrm{CMA}^{+}$and $\mathrm{CMA}^{-}$, were DAPI positive but variation between $P$. mugo and $P$. uncinata is shown in the number of interstitial bands. Although DAPI is specific for AT-rich sequences, recent studies demonstrated that DAPI bands also coincide with different kinds of heterochromatin (Barros e Silva and Guerra 2010). DAPI signals could be composed of different AT-rich repetitive families such as telomere-like, Atype telomere or degenerated A-telomere sequences, but can also be constituted from unknown repetitive sequences (Shibata et al. 2005). Barros e Silva and Guerra (2010) demonstrated that DAPI banding mostly varied on applied DAPI procedures before or after FISH experiments. After FISH experiments DAPI indicates constitutive heterochromatin (Bogunic et al. 2006, 2011). Some authors suggest that the variation in DAPI signals can be explained by the expansion of microsatellite sequences, or integration and retrotransposition of extrachromosomal DNA short repeats (Shibata et al. 2005). Whatever their basis, DAPI patterns indicate more pronounced variation between the two species than the other molecular-cytogenetic markers used in the study. Finally, slight variation in the number of DAPI bands could have occurred during the technical procedures, since fine DAPI signals quickly fade and might therefore be overlooked during fluorescence exposure.

\subsection{Population genome size analysis}

Flow cytometry revealed stable genome size, with relatively moderate coefficients of variation among the 22 populations and high resolution fluorescence histograms (c.v. 0.82$3.89 \%$ ). The protocol produced relatively little debris and reliable determination of DNA quantities, even with leaf material. Fresh seed material is sometimes recommended over leaf material since it does not contain staining inhibitors in the cytosol (Sliwinska et al. 2005). However, in our previous paper on $P$. nigra genome size analysis, we used pine megagametophytes (1C) from fresh seeds as the data source, and the coefficients of variation also fell within the same range of variation (c.v. 3-4\%) as for the leaf material (Bogunic et al. 2007). Compared with previously published reports on $P$. mugo genome size, we found slightly different values from those of Greilhuber (1986) (40.36 pg) and Ohri and Khoshoo (1986) (40.20 pg). The authors used Feulgen cytophotometry and a different reference standard (Allium cepa Alisa Craig). Our previous study on one $P$. mugo population found $42.79 \mathrm{pg}$ (Bogunic et al. 2003). The present study dealt with many more populations and revealed almost the same value (42.56 pg) for $P$. mugo accessions, indicating consistency in genome measurement between these different time periods. Discrepancies in genome size values between works by different authors were recently verified by Marum et al. (2009), who studied embryogenic cell lines of Pinus pinaster. The study showed genome size variation among their own results and those of the other authors ranging from $8 \%$ (Grotkopp et al. 2004) to $21 \%$ (Ohri and Khoshoo 1986) and 27\% (Horjales et al. 2003). Despite progress over the last decade in the methodology of genome size determination, it is clear that this field still suffers from contradictory reports between different laboratories. 
Slight differences were found among three $(p<0.01)$ or between two $(p<0.001)$ populations using Tukey's tests. No significant differences were observed using Scheffe's test, which is more appropriate but less sensitive to possible experimental errors during measurements. Therefore, we can conclude that $P$. mugo populations maintain a stable genome size at a large geographical scale across the mountainous areas of the Balkans and Alps (Table 1). According to Leitch et al. (1998) pines are classified into plant groups having 'very large' genomes in terms of nuclear DNA content and a large portion of their genomes consist of highly repetitive DNA fractions (Morse et al. 2009). At the present level of knowledge, the fluctuation of genome size values among the $P$. mugo populations could be ascribed to different retrotransposon families and their dynamics, such as integration and retrotransposition of extrachromosomal DNA short repeats within the genome (Williams et al. 2002; Morse et al. 2009).

Although genome size is correlated with many biological and life history attributes in pines (Grotkopp et al. 2004), the absence of any relationships with geographical factors in P. mugo suggests that variation in genome size occurs randomly, due to various cytomolecular mechanisms within the genome. This is not surprising since the populations of $P$. mugo analysed are restricted to subalpine and alpine belts, and such a spatial distribution is characterized by extreme variations in ecological parameters. Extreme environmental conditions may have important effects on different genetic processes, such as genetic drift and inbreeding, in isolated populations in alpine and subalpine belts (Slavov and Zhelev 2004), causing high within- and low among-population differentiation (Monteleone et al. 2006). No differences in genome size that could have arisen from such pressures were observed between $P$. uncinata and P. mugo in our study. Monteleone et al. (2006), using RAPD molecular markers, found no significant genetic structuring differences between populations of $P$. mugo and $P$. uncinata. The authors assumed that the divergence time period was too short to have generated profound interspecific differences in relation to ancestral populations since the Neogene and during the Pleistocene. Heuertz et al. (2010), using chloroplast microsatellites, also confirmed the absence of species differentiation; suggesting geographic distance and recolonization processes from different glacial refugia were the key factors driving genetic differentiation of populations within the complex, rather than clear delimitation into P. mugo and P. uncinata taxa. Our sampling strategy was based on 21 populations of $P$. mugo and one of $P$. uncinata. The constant genomes' uniformity within P. mugo populations and between $P$. mugo and P. uncinata likely imply the absence of differentiation even in case of extended P. uncinata samples. However, our conclusions are referred only to analysed populations.

\subsection{Concluding remarks}

The present results point out that despite the clear morphological differentiation between $P$. mugo and $P$. uncinata these two species have conserved chromosomal organization and genome size values. Evolutionary forces shaping chromosomal organization and genome size did not profoundly differentiate the genomes of these pine species. Observed variation in CMA and DAPI heterochromatin patterns indicate ongoing divergence processes. Our data do not provide the evidence for specific status of the two pines but rather go in favour to subspecific ranks given their clear morphological differentiation and allopatric distribution. More substantial differences would be expected during the independent divergence and adaptation through the evolutionary history of these species.

Acknowledgements The authors wish to thank D. Ballian, B. Frajman, P. Schönswetter, J. Vallès, T. Garnatje and B. Heinze for collecting seed material and $\mathrm{O}$. Robin and $\mathrm{O}$. Catrice for technical assistance. The authors are also indebted to the Federal Ministry of Education and Science of Bosnia and Herzegovina (no. 03-39-5980-194-2/08), CNRS (Centre National de la Recherche Scientifique, France) and the NATO project Science for Peace (no. 983838) for their funding of this project. F.B. gratefully acknowledges support from the NORAGRIC (Department of International Environment Studies, Norwegian University of Life Sciences, Aas, Norway). We are very grateful to Dr. Helen McCombieBoudry for the English revision of manuscript.

\section{References}

Barros e Silva AE, Guerra M (2010) The meaning of DAPI bands after C-banding and FISH procedures. Biotech Histochem 85 (2):115-125. doi:10.1080/10520290903149596

Bennett MD, Leitch IJ (2005) Genome size: a field in focus. Ann Bot 95:1-6

Bogunic F, Muratovic E, Brown SC, Siljak-Yakovlev S (2003) Genome size of five Pinus from Balkan region. Plant Cell Rep 22:59-63

Bogunic F, Muratovic E, Siljak-Yakovlev S (2006) Chromosomal differentiation of Pinus heldreichii and Pinus nigra. Ann For Sci 63:267-274

Bogunic F, Muratovic E, Ballian D, Siljak-Yakovlev S, Brown S (2007) Genome size stability of five subspecies of Pinus nigra Arnold s.l. Env Exp Bot 59:354-360

Bogunić F, Siljak-Yakovlev S, Muratović E, Ballian D (2011) Different karyotype patterns among allopatric Pinus nigra (Pinaceae) populations revealed by molecular cytogenetics. Plant Biol 13(1):194-200

Boratyńska K, Bobowicz MA (2001) Pinus uncinata Ramond taxonomy based on needle characters. Plant Syst Evol 227:183194

Boratyńska K, Boratyński A (2007) Taxonomic differences among closely related pines Pinus sylvestris, $P$. mugo, $P$. uncinata, $P$. rotundata and P. rhaetica. Flora 202:555-569

Christensen KI (1987) Taxonomic revision of the Pinus mugo complex and $P . x$ rhaetica ( $P$. mugo $x$ sylvestris) (Pinaceae). Nord J Bot 7:383-408

Doležel J, Bartoš J, Voglmayr H, Greilhuber J (2003) Nuclear DNA content and genome size of trout and human. Cytometry 51A: $127-128$ 
Eckert AJ, Hall BD (2006) Phylogeny, historical biogeography, and patterns of diversification for Pinus (Pinaceae): phylogenetic tests of fossil-based hypothesis. Mol Phyl Evol 40:166-182

Galbraith D, Harkins K, Maddox J, Ayres N, Sharma D, Firoozabady E (1983) Rapid flow cytometric analysis of the cell cycle in intact plant tissues. Science 220:1049-1051

Gaussen H, Webb DA, Heywood HV (1993) Pinus. In: Tutin GH, Heywood HV, Burges NA, Moore DM, Valentine DH, Walters SM, Webb DA (eds) Flora Europaea, vol 1. Cambridge University Press, Cambridge, pp 40-44

Gerlach WL, Dyer TA (1980) Sequence organization of the repeat units in the nucleus of wheat which contain 5S rRNA genes. Nucleic Acids Res 8:4851-4865

Gernandt DS, Lopez GG, Garcia SO, Liston A (2005) Phylogeny and classification of Pinus. Taxon 54(1):29-42

Greilhuber J (1986) Severly distorted Feulgen-DNA amounts in Pinus (Coniferophytina) after nonnadditive fixations as a result of meristematic self-tanning with vacuole contents. Can J Gen Cytol 28:409-415

Grotkopp E, Rejmanek M, Sanderson MJ, Rost TL (2004) Evolution of genome size in pines (Pinus) and its life-history correlates: supertree analysis. Evolution 58:1705-1729

Guerra M, Galvão Bezerra dos Santos K, Barros e Silva AE, Ehrendorfer F (2000) Heterochromatin banding patterns in Rutaceae-Aurantioideae - a case of parallel chromosomal evolution. Am J Bot 87:735-747

Hamerník J, Musil I (2007) The Pinus mugo complex-its structuring and general overview of the used nomenclature. J For Sci 53:253-266

Heuertz M, Teufel J, González-Martínez SC, Soto A, Fady B, Alía R, Vendramin GG (2010) Geography determines genetic relationships between species of mountain pines (Pinus mugo complex) in western Europe. J Biogeogr 37:541-556

Hizume M, Shibata F, Matsuki Y, Garajova M (2002) Chromosome identification and comparative analysis of four Pinus species. Theor Appl Genet 105:491-497

Horjales M, Redondo N, Rodríguez M (2003) Cantidades de DNA nuclear en árbóreas y arbustos. NACC Nova Acta Cient Compost Biol 13:20-33

Karvonen P, Karjalainen M, Savolainen O (1993) Ribosomal RNA genes in Scots pine (Pinus sylvestris L.): chromosomal organization and structure. Genetica 88:59-68

Leitch IJ, Chase MW, Bennett MD (1998) Phylogenetic analysis of DNA C-values provides evidence for a small ancestral genome size in flowering plants. Ann Bot 82(suppl A):85-94
Liu Z-I, Zhang D, Hong D-Y, Wang X-R (2003) Chromosomal localization of $5 \mathrm{~S}$ and $18 \mathrm{~S}-5.8 \mathrm{~S}-25 \mathrm{~S}$ ribosomal DNA sites in five Asian Pinus species using fluorescence in situ hybridization. Theor Appl Genet 106:198-204

Lubaretz O, Fuchs J, Ahne R, Meister A, Schubert I (1996) Karyotyping of three Pinaceae species via fluorescent in situ hybridization and computer-aided chromosome analysis. Theor Appl Genet 92:411-416

Marcysiak K, Boratyński A (2007) Contribution to the taxonomy of Pinus uncinata (Pinaceae) based on cone characters. Plant Syst Evol 264:57-73

Marie D, Brown SC (1993) A cytometric exercise in plant DNA histograms with $2 \mathrm{C}$ values for 70 species. Biol Cell 78:41-51

Marum L, Loureiro J, Rodriguez E, Santos C, Oliviera MM, Miguel C (2009) Flow cytometric and morphological analyses of Pinus pinaster somatic embryogenesis. J Biotech 143:288-295

Monteleone I, Ferrazzini D, Belletti P (2006) Effectiveness of neutral RAPD markers to detect genetic divergence between the subspecies uncinata and mugo of Pinus mugo Turra. Silva Fenn 40:391-406

Morse AM, Peterson DG, Islam-Faridi NM, Smith EK, Magbanua Z, Garcia SA, Kubisiak TL, Amerson AV, Carlson JE, Nelson CD, Davis JM (2009) Evolution of genome size and complexity in Pinus. PLoS ONE 4(2):e4332. doi:10.1371/journal.pone.0004332

Murray BG (1998) Nuclear DNA amount in gymnosperms. Ann Bot 82(Supplement A):3-15

Ohri D, Khoshoo TN (1986) Genome size in gymnosperms. Plant Syst Evol 153:119-132

Prus-Glowacki W, Bujas E, Ratyńska H (1998) Taxonomic position of Pinus uliginosa Neumann as related to other taxa of Pinus mugo complex. Acta Soc Bot Pol 67:269-275

Shibata F, Matsusaki Y, Hizume M (2005) AT-rich sequences containing Arabidopsis-type telomere sequence and their chromosomal distribution in Pinus densiflora. Theor Appl Genet 110:1253-1258

Siljak-Yakovlev S, Cerbah M, Coulaud J, Stoian V, Brown SC, Zoldos V, Jelenic S (2002) Nuclear DNA content, base composition, heterochromatin and rDNA in Picea omorika and Picea abies. Theor Appl Genet 104:505-512

Slavov GT, Zhelev P (2004) Allozyme variation, differentiation, and inbreeding in populations of Pinus mugo in Bulgaria. Can J For Res 34:2611-2617

Sliwinska E, Zielinska E, Jedrzejczyk I (2005) Are seeds suitable for flow cytometric estimation of plant genome size? Cytometry 64(A):72-79

Williams C, Joyner K, Auckland L, Johnston S, Price H (2002) Genomic consequences of interspecific Pinus spp. hybridization. Biol J Linn Soc 75:503-508 